\title{
Case Report: Median Nerve Cavernous Hemangioma
}

Mohammed Al-Garnawee ${ }^{1}$, Marwan Najjar ${ }^{{ }^{\star}}$

1. Department of Surgery, Faculty of Medicine, American University of Beirut, Beirut, Lebanon.

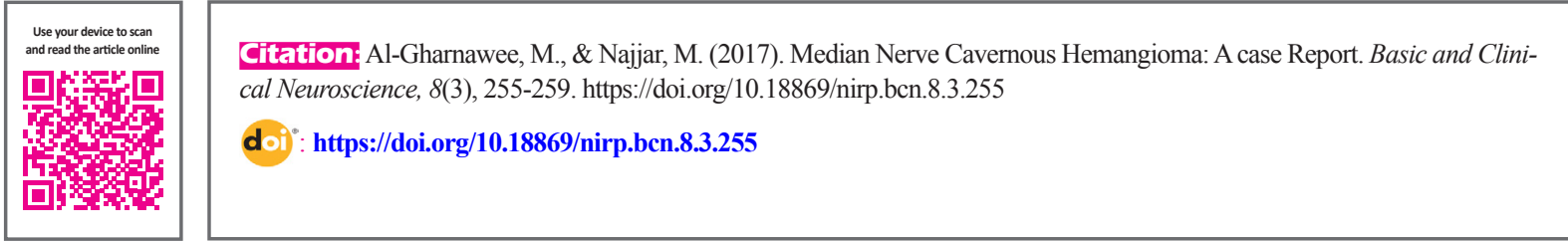

Article info:

Received: 07 November 2016

First Revision: 09 January 2017

Accepted: 24 January 2017

Key Words:

Median nerve,

Cavernous hemangioma,

Peripheral nerve lesions,

Entrapment syndromes

\begin{abstract}
A B S T RA C T
Hemangiomas of the median nerve are extremely rare; only 12 cases have been reported in the literature. We discuss a patient who presented with paresthesia and pain along the distribution of the left median nerve secondary to a cavernoma of the proximal part of the nerve as suspected on MRI scan. Total removal of the mass was achieved with immediate relief of the symptoms and no neurologic deficit. We conclude that despite being quite rare, the diagnosis of occult vascular lesions of peripheral nerves such as the median nerve, should be considered, especially when other common pathologies are excluded.
\end{abstract}

\section{Introduction}

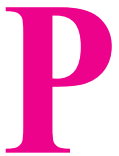

eripheral nerve tumors are rare. They can be classified according to their origin as either nerve sheath tumors or nonneural sheath tumors (Kim, Murovic, Tiel, Moes, \& Kline, 2005). The most frequent nerve sheath tumors are benign and include schwannomas and neurofibromas (Schroder, 2001). Benign non-neural sheath tumors mainly include lipomas and vascular tumors. Malignant peripheral nerve sheath tumors are much less frequent and could include metastasis. Very few cases of vascular lesions involving the peripheral nervous system have been reported. In this paper, we report on a hemangioma involving the sheath of the left median nerve.

\section{Case Report}

A 43-year-old female presented with 18 months history of left upper extremity paresthesia and pain along the median nerve distribution, which got progressively more severe over time, though with no motor weakness. The patient failed medical treatment. EMG and nerve conduction testing were normal. Magnetic resonance imaging (MRI) results of the cervical spine were within normal limits. MRI of the left upper extremity showed a 9-mm mass arising from the left median nerve suggestive of a cavernous hemangioma (Figure 1).

On operation, we managed to identify a small firm black-looking mass closely related to the sheath of the left median nerve in the upper arm (Figure 2a). After careful dissection, and under microscopic magnifica-

* Corresponding Author:

Marwan Najjar, PhD

Address: Department of Surgery, Faculty of Medicine, American University of Beirut, Beirut, Lebanon.

Tel: +961 (30) 43704

E-mail:mwnajjar@yahoo.com 


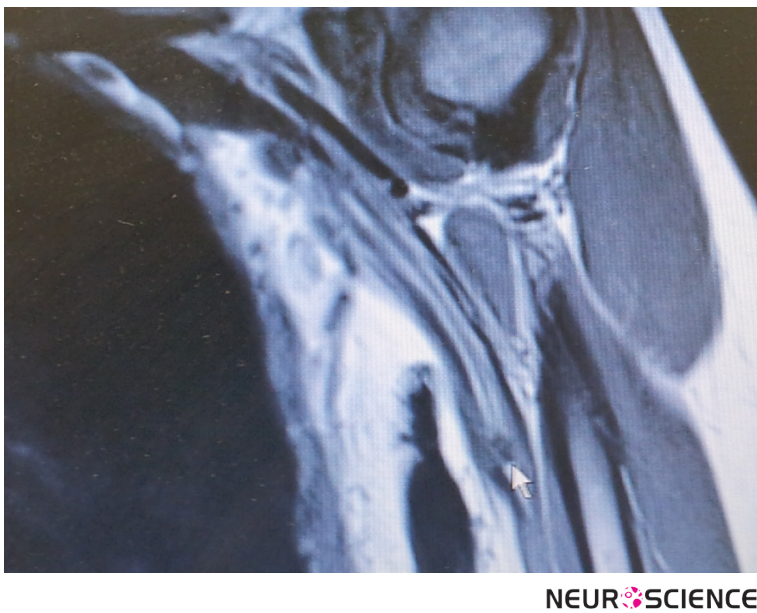

Figure 1. Magnetic resonance imaging of the median nerve showing a hypointense lesion of the nerve at the level of the midarm (arrow).

tion, a complete resection of the mass was achieved (Figure 2b). Postoperatively, the patient reported instant relief of her symptoms with no neurological deficit. Histopathological examination showed dilated venous channels with intervening fibroconnective tissue suggestive of cavernous hemangioma (Figure 3). Upon 6 months of follow up, the patient remained asymptomatic without signs of recurrence on MRI.

\section{Discussion}

Benign vascular tumors originating from peripheral nerves are rare. The median nerve is most commonly affected, followed by the tibial, ulnar, digital, sciatic, and superficial peroneal nerves (Chatillon, Guiot, \& Jacques,

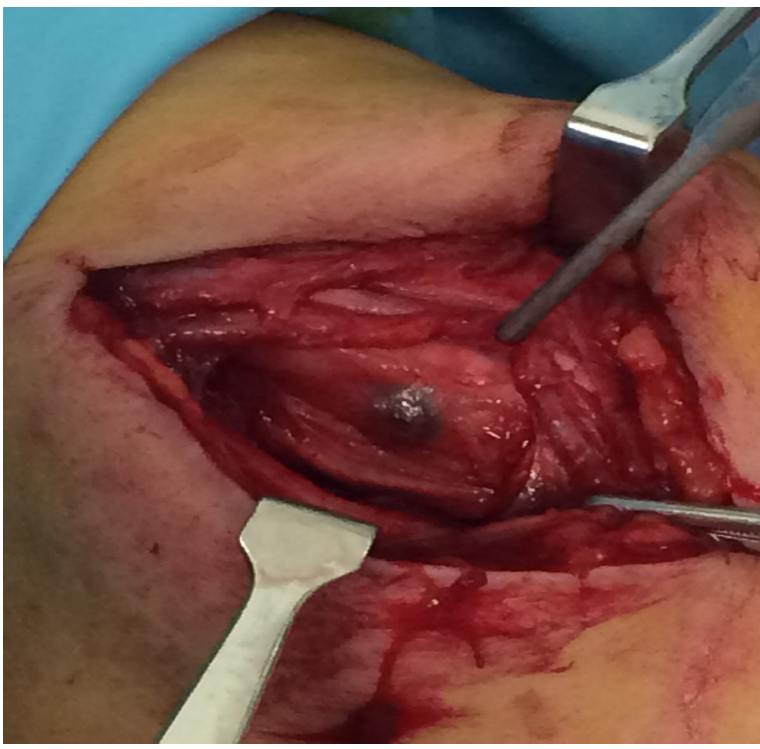

2007). Only 12 cases of median nerve hemangiomas are reported in the literature (Table 1) (Coessens, De Mey, Lacotte, \& Vandenbroeck, 1991; Dogramaci, Kalaci, Sevinç, \& Yanat, 2014; Kojima, Ide, Marumo, Ishikawa, \& Yamashita, 1976; Louis \& Fortin, 1992; Oztekin \& Karaarslan, 2003; Patel, Tsai, \& Kleinert, 1986; Peled, Iosipovich, Rousso, \& Wexler, 1980; Petrovici, 1980; Prosser \& Burke, 1987; Sato, 1913; Vekris et al., 2008).

According to the nerve structure involved, these tumors can be classified into 3 types. Type I is an intraneural extrafascicular malformation that is relatively easily removed with magnification. Type II is an intrafascicular encompassing type that is deemed unresectable because of the possible loss of nerve function secondary to the required dissection. Type III has both intraneural and extraneural components (Louis \& Fortin, 1992) (Table 2).

In the majority of cases, the patients report a palpable mass along the path of the median nerve. Carpal tunnel like syndrome is the most common finding and one case had Raynaud's phenomenon as an associated presenting symptom (Prosser \& Burke, 1987). The differential diagnosis of such lesions includes lipoma, lipofibroma, hamartoma, and intraneural schwannoma (Chatillon et al., 2007).

The diagnostic work up of such lesions includes ultrasonography, nerve conduction studies, and MRI. Regarding sonography, most peripheral nerve sheath tumors share the common features of being hypoechoic and homogeneous, with posterior acoustic enhancement and peripheral nerve continuity, where the finding of

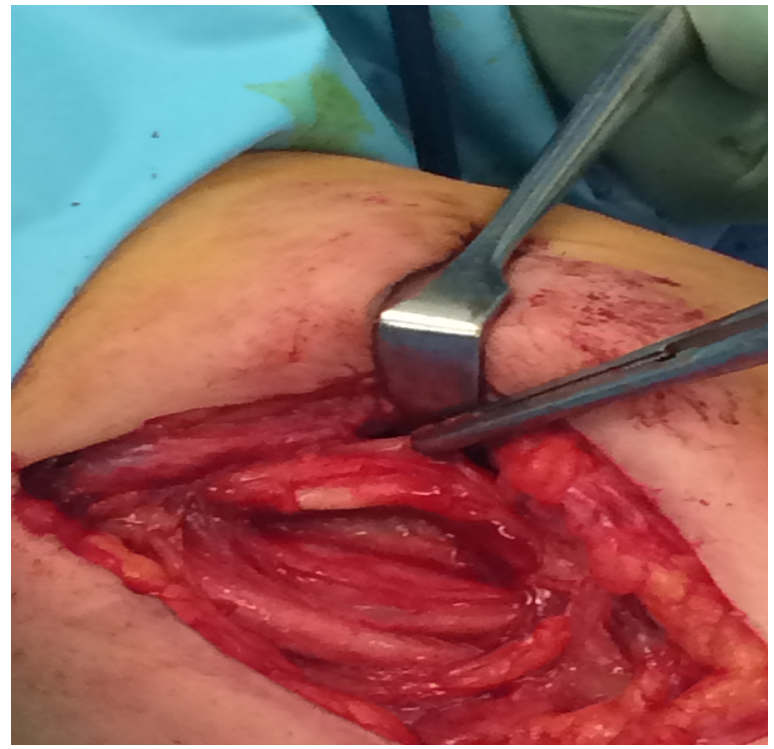

NEUR:SCIENCE

Figure 2. Intraoperative picture after exposure of the median nerve. a: A small black lesion is seen involving the median nerve. b: Complete microsurgical removal of the lesion. 

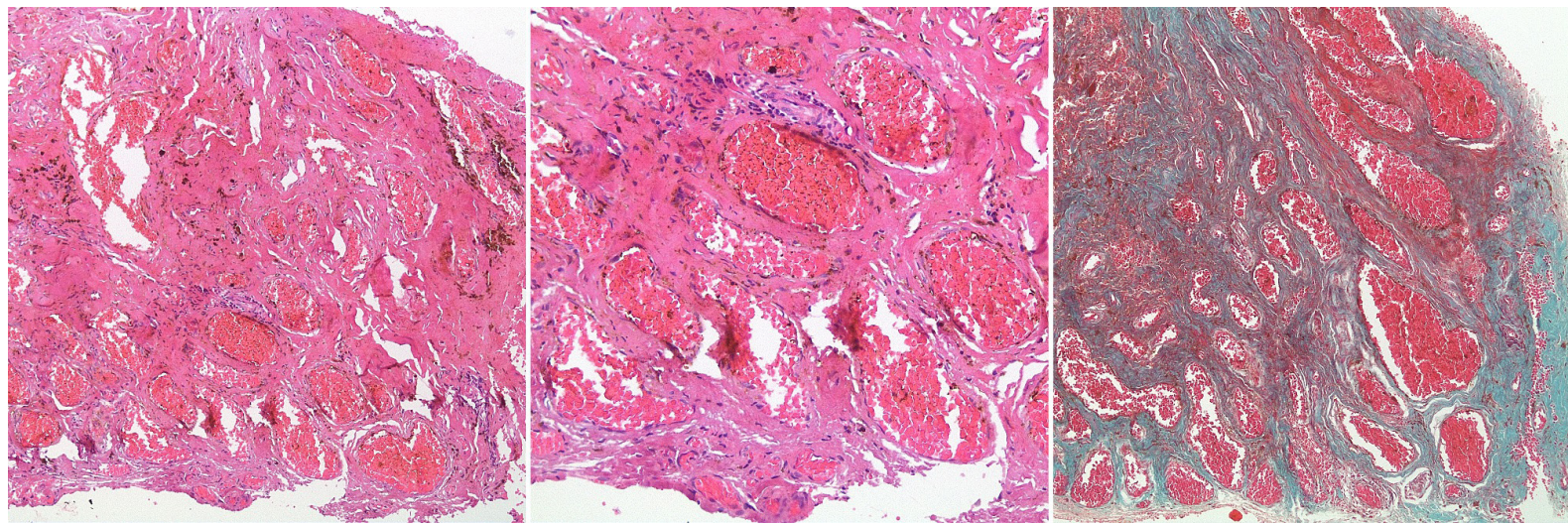

NEUR:SCIENCE

Figure 3. Peripheral (median) nerve epineural hemangioma characterized by dilated venous channels with intervening fibroconnective tissue (Left and middle panel H\&E, 100x \& 200x; Right panel Trichrome Stain, 100x).

Table 1. Median nerve cavernous hemangiomas reported in the literature.

\begin{tabular}{|c|c|c|c|c|}
\hline Outcome & Procedure & Location & Age/Gender & Author \\
\hline $\begin{array}{l}\text { No recurrence, asymptomatic at } 6 \\
\text { months follow up }\end{array}$ & $\begin{array}{l}\text { Intra-fascicular dissection and } \\
\text { resection of tumor }\end{array}$ & Carpal tunnel & $12 / \mathrm{M}$ & Coessens et al. (1991) \\
\hline No recurrence in two years follow up & Resection & Carpal tunnel & $14 / F$ & Dogramaci et al. (2008) \\
\hline $\begin{array}{c}\text { Neurologically normal at six weeks after } \\
\text { surgery }\end{array}$ & Non-specified type of resection & Carpal tunnel & $19 / F$ & Kojima et al. (1976) \\
\hline Asymptomatic for six months follow up & Resection & $\begin{array}{l}\text { Proximal } 1 / 3 \text { of the } \\
\text { forearm }\end{array}$ & $21 / N A$ & Louis et al. (1992) \\
\hline No recurrence in six months & Resection & Carpal tunnel & $35 / F$ & Oztekin et al. (2003) \\
\hline Remained symptomatic & Multiple excisions & Carpal tunnel & $4 / \mathrm{F}$ & Patel et al. (1986) \\
\hline No recurrence & $\begin{array}{l}\text { Recurrence at } 2 \text { years after intra- } \\
\text { neural dissection/ patient then had } \\
\text { resection with sural nerve graft }\end{array}$ & Carpal tunnel & $15 / F$ & Patel et al. (1986) \\
\hline $\begin{array}{l}\text { Hyperesthesia improved after three } \\
\text { weeks and weakness which improved } \\
\text { gradually }\end{array}$ & $\begin{array}{l}\text { Partial excision, followed by en } \\
\text { bloc resection after } 3 \text { years }\end{array}$ & Carpal tunnel & $16 / F$ & Peled et al. (1980) \\
\hline No recurrence in one year & Resection & Carpal tunnel & $22 / F$ & Petrovici. (1980) \\
\hline $\begin{array}{l}\text { Fourth Recurrence treated conserva- } \\
\text { tively } \\
\text { Decrease sensation in thumb and } \\
\text { index }\end{array}$ & Multiple excisions & Carpal tunnel & $13 / F$ & Prosser et al. (1987) \\
\hline Ulnar parasthesia & $\begin{array}{l}\text { Resection of tumor with involved } \\
\text { nerve segment }\end{array}$ & Carpal tunnel & $64 / M$ & Sato. (1913) \\
\hline No recurrence in three years follow up & Resection & Carpal tunnel & $10 / F$ & Vekris et al. (2008) \\
\hline
\end{tabular}

NEUR:SCIENCE

Table 2. Classification of peripheral nerve vascular malformations.

\begin{tabular}{cc}
\hline Types & Extent of Involvement \\
\hline I & Intraneural extrafascicular malformation \\
II & Intrafascicular \\
\hline
\end{tabular}


peripheral nerve continuity indicates peripheral nerve sheath tumor as the cause (Reynolds et al., 2004).

On MRI, magnetic resonance characteristics reported in the literature include hyperintense signal on T1- and T2- weighted images with fat suppression sequences. These lesions are also noted to enhance after gadolinium administration (Dogramaci et al., 2014). Magnetic Resonance Imaging (MRI) gives useful information regarding the anatomic location, size, and relationship of intraneural hemangioma of the median nerve to surrounding structures and may help differentiate between various tumor types (Ergin, Druckmiller, \& Cohen, 1998).

Treatment of such lesions with a conservative approach usually fails and surgery is the treatment of choice (Dogramaci et al., 2014). Total resection of intraneural hemangiomas is curative when possible, whereas partial resection may relieve symptoms. Recurrence, however, may occur which may require en bloc nerve resection and repair with nerve graft (Patel et al., 1986). Cases in which the hemangioma is intraneural but essentially extrafascicular tend to do well with local excision alone (Louis \& Fortin, 1992). Most reported peripheral nerve hemangiomas are of the cavernous type although the capillary subtype has been identified. The consensus as to the histogenesis of peripheral nerve hemangioma favors the origin to be in the capillary bed of the epineurium with subsequent extension to the nerve trunk (Schroder, 2001).

Our case, like most of the previously reported cases, is a female with similar presenting symptoms and the same histopathological type (cavernous hemangioma). However, she is older than all the cases except one case. Unlike the majority of cases where the lesions were situated near the carpal tunnel or the palm, our case is the first case of cavernous hemangioma involving the median nerve in a proximal location in the arm.

\section{Conclusion}

In conclusion, despite the rarity of such lesions, cavernous hemangioma should be considered in the differential diagnosis of median nerve lesions, especially in young females with unexplained pain, paresthesia, and a palpable lesion. The diagnosis of such lesions involves a thorough history and physical exam as well as appropriate imaging modalities, especially ultrasonography and MRI. Careful intraoperative dissection of such lesions is important for preserving nerve function and usually results in excellent outcome, whereas en bloc resection with grafting should be reserved for complicated or recurrent cases.

\section{Acknowledgements}

This research did not receive any specific grant from funding agencies in the public, commercial, or not-forprofit sectors.

\section{Conflict of Interest}

Authors declared no conflicts of interest.

\section{References}

Châtillon, C. E., Guiot, M. C., \& Jacques, L. (2007). Lipomatous, vascular, and chondromatous benign tumors of the peripheral nerves. Neurosurgical Focus, 22(6), 1-8. doi: 10.3171/ foc.2007.22.6.19

Coessens, B., De Mey, A., Lacotte, B., \& Vandenbroeck, D. (1991). Carpal tunnel syndrome due to an haemangioma of the median nerve in a 12-year-old child. Annales de Chirurgie de La Main et Du Membre Supérieur, 10(3), 255-257. doi: 10.1016/ s0753-9053(05)80292-3

Doğramac1, Y., Kalac1, A., Sevinç, T., \& Yanat, A. (2014). Intraneural hemangioma of the median nerve: A case report. Jour nal of Brachial Plexus and Peripheral Nerve Injury, 03(1), 95-99. doi: 10.1186/1749-7221-3-5

Ergin, M. T., Druckmiller, W. H., \& Cohen, P. (1998) Intrinsic hemangiomas of the peripheral nerves report of a case and review of the literature. Connecticut Medicine, 62(4), 209-213. PMID: 9611417

Kim, D. H., Murovic, J. A., Tiel, R. L., Moes, G., \& Kline, D. G. (2005). A series of 146 peripheral non - neural sheath nerve tumors: 30-year experience at Louisiana State University Health Sciences Center. Journal of Neurosurgery, 102(2), 256-266. doi: 10.3171/jns.2005.102.2.0256

Kojima, T., Ide Y., Marumo, E., Ishikawa, E., \& Yamashita, H (1976). Haemangioma of median nerve causing carpal tunnel syndrome. Hand, 8(1), 62-65. doi: 10.1016/0072-968x(76)900632

Louis, D. S., \& Fortin, P. T. (1992). Perineural hemangiomas of the upper extremity: Report of four cases. Journal of Hand Surgery, 17(2), 308-311. doi: 10.1016/0363-5023(92)90412-i

Oztekin, H. H., \& Karaarslan, A. A. (2003) Carpal tunnel syndrome due to a cavernous hemangioma of the median nerve. Acta Orthopaedica et Traumatologica Turcica. 37(2), 170-172. PMID: 12704258

Patel, C. B., Tsai, T. M., \& Kleinert, H. E. (1986). Hemangioma of the median nerve: A report of two cases. The Journal of Hand Surgery, 11(1), 76-79. doi: 10.1016/s0363-5023(86)80108-3

Peled, I., Iosipovich, Z., Rousso, M., \& Wexler, M. R. (1980). Hemangioma of the median nerve. Journal of Hand Surgery, 5(4), 363-365. doi: 10.1016/s0363-5023(80)80177-8 
Petrovici, V. (1980) Cavernous hemangioma of the palm with symptoms resembling carpal tunnel syndrome. Zeitschrift fur Plastische Chirurgie, 4(1), 40-47. PMID:6250298

Prosser A. J., \& Burke F. D. (1987). Haemangioma of the median nerve associated with Raynaud's phenomenon. The Journal of Hand Surgery, 12(2), 226-228. doi: 10.1016/0266-7681(87)90019-

Reynolds, D. L., Jacobson, J. A., Inampudi, P., Jamadar, D. A., Ebrahim, F. S., \& Hayes, C. W. (2004). Sonographic characteristics of peripheral nerve sheath tumors. American Journal of Roentgenology, 182(3), 741-744. doi: 10.2214/ajr.182.3.1820741

Sato S. (1913). [About the cavernose angioma of the peripheral nervous system (German)]. Arch Klin Chir, 100, 553

Schröder J. M. (2001). Tumors of the peripheral nervous system, In: J. M. Schröder (Ed.), Pathology of Peripheral Nerves: An Atlas of Structural and Molecular Pathological Changes (pp. 307-329). Heidelberg: Springer.

Vekris, M. D., Stafilas, K. S., Zacharis, K. X., Xenakis, T. A., Soucacos, P. N., \& Beris, A. E. (2008). Intrinsic haemangioma of the median nerve: Report of a case and review of the literature. Microsurgery, 28(2), 89-90. doi: 10.1002/micr.20456 